\title{
Critical analysis of an accident and emergency ward
}

\author{
T H Rainer, I J Swann, R Crawford
}

\begin{abstract}
Objectives-To describe the work, both qualitatively and quantitatively, of an accident and emergency (A\&E) ward, and discuss some of the advantages and disadvantages associated with this ward.

Methods-An observational study was carried out of all patients admitted to the A\&E ward of Glasgow Royal Infirmary from 1 January 1992 to 31 December 1992. Epidemiological and management data were collected for all patients admitted. Results-There were 2460 admissions, of which $69 \%$ were related to trauma and $45 \%$ to head injury; $47 \%$ of the patients had consumed alcohol before admission. Accidental trauma was the commonest reason for admission (57\%), followed by assault (33\%). Ninety two per cent of admissions stayed for less than $3 \mathrm{~d}$, but $33 \%$ of the workload was spent on a small number of patients admitted for longer than $7 \mathrm{~d}$.

Conclusions-This A\&E ward presents a significant workload, and some of its most serious problems lie with those patients who stay longer than $72 \mathrm{~h}$. The safe and effective use of the ward depends upon it being well resourced, along with the department it serves.

(F Accid Emerg Med 1996;13:325-329)
\end{abstract}

Key terms: observation ward; emergency medicine

Since the first recommendations regarding accident and emergency (A\&E) wards in $1960^{\circ}$ there has been a gradual development in this service. The function of the ward has been described for some centres ${ }^{2}$ and the workload with cost implications has been assessed in others. ${ }^{3-5}$ However, considerable differences exist between hospitals, especially regarding the type and proportion of diagnostic categories admitted, the number that admit children, ${ }^{6}$ and those that are exclusively paediatric.? Despite the initial recommendation and suggestions (dating from as far back as 1981) that "no department can be considered safe without them" 8 and "no hospital should be allowed to advertise for a consultant post in $A \& E$ medicine unless such a provision has been made", 9 only $50 \%$ of departments have this facility. ${ }^{6}$ Almost without exception all describe the A\&E ward as a "short stay" or "observation" ward.

We describe a unique ward that may fit neither the category of short stay nor of observation, and discuss the value and problems associated with this ward run by $A \& E$ staff.

\section{Methods}

DESCRIPTION OF THE SERVICE

Glasgow Royal Infirmary is an 800 bedded teaching hospital situated in an Urban area. As one of several hospitals serving the 700000 population of Glasgow, it provides a service to the city centre and the deprived east end, and has its own catchment population of about 200 000. The A\&E department sees approximately 75000 new patients per year. Most of the city's hostels for homeless people are within the catchment area.

The department functions not only as an $\mathrm{A} \& \mathrm{E}$ unit but also as an assessment and processing area for all acute admissions. During the period of the study there were three consultants, three middle grade staff, 12 senior house officers (SHOs), and one junior house officer (JHO). One consultant had a major interest in hand surgery; another had a special interest in head injured patients.

\section{THE ACCIDENT AND EMERGENCY WARD}

Towards the close of 1991, as a result of a reorganisation of services, the number of $A \& E$ beds was reduced from 32 to 20 , comprising 13 male, four female, and three cubicles. A\&E consultants assumed overall charge of the ward and a ward round was conducted once a day every morning, including the weekend, either by the consultant or a middle grade staff member and an SHO. Later in the day the middle grade doctor would review specific patients identified earlier on the round who might be fit for discharge. A JHO was attached to the ward from 08:00-17:00 hours on Monday to Friday. Out of hours cover was provided by SHOs from the department.

Current nurse staffing on the ward amounts to 17.37 whole time equivalents (WTE). A WTE equals 37.5 hours. There is one grade G sister (1.0 WTE), one grade F staff nurse (1.0 WTE), grade E (5.92 WTE) and D (4.55 WTE) staff nurses, and grade A auxiliary nurses (4.90 WTE). There is one part time ward clerk.

The ward provides the service for the following categories:

(1) Acute A\&E admissions-head injury, maxillofacial injury, chest trauma (soft tissue, rib fracture, haemothorax and pneumothorax requiring chest drains but not further cardiothoracic expertise), other soft tissue injuries, cellulitis, abscesses, wounds and alcohol problems complicating such trauma

(2) An acute hand service-under the care of one of the consultants

(3) A rehabilitation service for patients with severe head injury who are returned from the regional neurosurgical centre 
(4) An overflow area for other specialties. In this case patients remained under the care of the specialist consultant on call. These include some simple medical problems, simple overdoses and pure alcohol intoxication.

The ward functions as more than a low dependency unit, both observing and managing persons with acute injuries of moderate severity including those with fractured skull, fractured ribs, and penetrating chest injuries. The nursing staff are trained for managing patients with minor, moderate, and severe head injuries, and criteria for referral to neurosurgery are well understood. Paediatric patients were also admitted under the care of $A \& E$ but to another ward and so are not included in this study.

\section{STUDY PROTOCOL}

This prospective study ran for a period of 12 months: 1 January to 31 December 1992 . All patients admitted to the $A \& E$ ward were included. A proforma was completed by a ward doctor before the patient was discharged. The diagnosis was discussed at the ward round on the morning of discharge and training was provided regarding the completion of the form. Coding was performed using an abbreviated version of the international classification of diseases with revision (ICD-9cm).${ }^{10}$ A separate record was kept by the nurses of every one who was admitted and this was used to double check so that few patients were missed.

The following data were recorded: epidemiological - age; sex; postal code; specialty; diagnostic categories; external cause of injury (E) $\operatorname{code}^{11}{ }^{12}$; association with alcohol; management: - procedures; length of stay; follow up and outcome.

\section{DEFINITIONS}

Moderately severe head injury was defined as: (1) fractured skull; (2) posttraumatic amnesia (PTA) of greater than one hour and less than $24 \mathrm{~h}$, and/or (3) a patient with depression of either the verbal or motor response when examined within $6 \mathrm{~h}$ of injury with no evidence of significant alcohol or drug ingestion and who subsequently made a sufficiently good recovery to be discharged from the ward within $48 \mathrm{~h}$.

With PTA of less than $9 \mathrm{~h}$ it is often difficult to attribute to head injury that which may be wholly or partially a result of alcohol or drug consumption. In such circumstances the best possible assessment is made and the patient coded appropriately.

Intoxication was usually judged with hindsight by considering a combination of various pieces of evidence-the clinical features of excessive alcohol ingestion, reference to the patient's notes, serum osmolality, general mental and physical incapacity, and clinical outcome.

\section{Results}

ATTENDANCES AND ADMISSIONS

Of the 74610 new patient presentations to the A\&E department in 1992, 17226 (23\%) were admitted; 2460 (3.3\% of all new patient
Table 1 Analysis of workload by primary diagnosis

\begin{tabular}{ll}
\hline Diagnosis & $\begin{array}{l}\text { Primary diagnosis in patients } \\
\text { admitted }\end{array}$ \\
\hline Traumatic & $737(30 \%)$ \\
Head injury & $295(12 \%)$ \\
Face and neck injury & $299(12 \%)$ \\
Other open wounds & $207(9 \%)$ \\
Other fractures/dislocations & $81(3 \%)$ \\
Chest injury & $67(3 \%)$ \\
Other soft tissue injuries & \\
Atraumatic & $368(15 \%)$ \\
Abscesses/cellulitis & $144(6 \%)$ \\
Alcohol intoxication & $139(6 \%)$ \\
Other/unknown & $110(4 \%)$ \\
Medical & $2447(100 \%)$ \\
Total &
\end{tabular}

^ Excludes head, face, neck and chest.

attendances) were admitted to the $\mathrm{A} \& \mathrm{E}$ ward. This accounted for $14.5 \%$ of all hospital admissions through A\&E.

Of the admissions to the ward, 2357 (94.7\%) were through the A\&E department. Twenty four severely head injured patients were returned from the Regional Neurosurgical Centre for rehabilitation. Although less than $1 \%$ of the total they are an important group accounting for a significant workload. Three of these patients remained for the duration of the study, being admitted before it started and being still in the ward at the close. The average daily admission rate was 6.7 (range 5.9 to 9.2 ), the busiest $24 \mathrm{~h}$ period being a Saturday. The rate of admission by month ranged from 29 to 40 per 1000 new patient attendances. The busiest month was July.

The male:female ratio was $3: 1$, and age distribution skewed in favour of youth (median 34 , interquartile range 24 to 53 , range 5 to 101 in years). Despite the fact that this was an adult ward, about 40 children (under 13 years) were admitted. The admission of children to this ward was an exception to usual practice and was due to the impending closure of and restricted access to the children's ward.

There was a high proportion of alcohol related blunt and penetrating injury and a significant number of drug related problems. Thirty four per cent of admissions for serious injury were due to assaults.

\section{ADMISSIONS BY PRIMARY DIAGNOSIS \\ Trauma}

Sixty nine per cent of admissions resulted from trauma. A breakdown of admissions by primary diagnosis is presented in table 1 . Diagnosis of head injury (ICD-9 $=800,801,850$, 873) was made in 1117 cases, although in 380 (34\%) it was a secondary or tertiary reason for admission. Of these, 99 had a skull fracture-64 had a radiological and clinical skull vault fracture, and 35 a clinical basal skull fracture. There were 653 patients with a diagnosis of concussion warranting admission, and 365 with a diagnosis of open scalp wound. There were a further 115 with a diagnosis of chest injury and 260 with hand injuries.

Influence of alcohol

The presence or absence of alcohol ingestion before admission was recorded in $83 \%$ of 
Table 2 Results expressed as a percentage of those with an external injury $(E)$ code

\begin{tabular}{lll}
\hline & $\begin{array}{l}\text { External injury }(E) \\
\text { code }\end{array}$ & Number of patients \\
\hline $\begin{array}{lll}\text { Accidents } \\
\text { Blunt }\end{array}$ & $\star$ & $446(49 \%)$ \\
$\begin{array}{l}\text { Penetrating } \\
\text { Animal bites/stings }\end{array}$ & 920.9 & $80(9 \%)$ \\
$\begin{array}{l}\text { Assaults } \\
\text { Blunt }\end{array}$ & 906.9 & $9(1 \%)$ \\
Penetrating & $960.0,963.0$ & $143(16 \%)$ \\
Self inflicted & 966 & $124(14 \%)$ \\
Other & 956 & $33(4 \%)$ \\
Total & & $76(8 \%)$ \\
\hline
\end{tabular}

NB These data apply to the second half of 1992.

$\star 888,814.7,819.0-819.3,819.7,826.1,916,917$.

cases. Of these, 964 (47.07\%) had consumed alcohol before attending $\mathrm{A} \& \mathrm{E}$. Intoxication (ICD-9 = 980) was noted in 391 $(15.9 \%)$ of all admissions.

\section{Aetiology of injury}

Aetiology of injury was recorded for the second half of the year. Of 911 records of injured patients, $58.8 \%$ were accidental and $32.9 \%$ resulted from assaults. Distribution of blunt and penetrating injury is shown in table 2 . Road traffic accidents (E 814.7826.1) accounted for $54(5.9 \%)$ of those coded, sport (E-917) for $15(1.7 \%)$, and falling objects (E 916) for 11 (1.2\%). Deliberate self harm (E 956 ) occurred in 33 cases $(3.6 \%)$. Over $22 \%$ of patients had penetrating injury, of which over a third were due to assaults (stabbings).

\section{Workload and length of stay}

Most of the admissions (92.6\%) stayed for 72 $\mathrm{h}$ or less. However, if one assesses workload in terms of bed-days per patient (that is, half a bed-day for stay less than $12 \mathrm{~h}$, and one bed-day per patient for each day spent on the ward), and then patients are grouped into categories of duration of stay, then a different picture emerges (see table 3 ). Over $33 \%$ of the overall workload was spent on a small number of patients (51) staying for longer than $7 \mathrm{~d}$. Less than $12 \%$ patients stayed for longer than $48 \mathrm{~h}$. thus justifying the term "short stay". If one considers the workload involved in those who stay longer than $72 \mathrm{~h}$ (defined in terms of bed-days) then they account for $43.8 \%$ of the ward's work. Nineteen per cent of the workload was taken up by three patients with chronic head injury who were not fit for rehabilitation in the community. All three stayed longer than $366 \mathrm{~d}$.

\section{Procedures}

In 1992 there were 505 surgical procedures. Incision and drainage was performed in 167 cases $(33 \%)$. There were 277 hand cases $(55 \%)$ requiring suture or exploration, tendon repair, removal of foreign bodies, or excision and debridement in theatre. In addition there were 61 manipulations of fracture or dislocation under anaesthesia (12\%). Chest drains were also inserted and managed.

\section{Discussion}

Initial publications regarding the purpose of the A\&E ward were positive. ${ }^{2-5}$ However, the
Table 3 Number of bed-days in relation to the duration of the stay

\begin{tabular}{lll}
\hline Duration of stay $(A)$ & No of patients $(B)$ & $\begin{array}{l}\text { No of bed-days } \\
(A \times B)\end{array}$ \\
\hline$<12$ hours & $661(24.06 \%)$ & $1128(19.50 \%)$ \\
$12-24$ hours & $1128(46.88 \%)$ & $1128(19.50 \%)$ \\
$24-48$ hours & $317(13.18 \%)$ & $634(11 \%)$ \\
$48-72$ hours & $121(5.03 \%)$ & $363(6.30 \%)$ \\
$4-7$ days & $128(5.32 \%)$ & $604(10.50 \%)$ \\
$8-14$ days & $34(1.41 \%)$ & $333(5.80 \%)$ \\
$25-364$ days & $14(<1 \%)$ & $488(8.40 \%)$ \\
$\geq 365$ days & $3(<1 \%)$ & $1095(19 \%)$ \\
Total & $2406(100 \%)$ & $5773(100 \%)$ \\
\hline
\end{tabular}

$68 \%$ occupancy ( 20 beds for 365 days $=7300$ ).

* Percentage expressed as a proportion of total number of beddays: $[(\mathrm{A} \times \mathrm{B}) / 5773] \times 100$.

provision of such a ward has both advantages and disadvantages. While cost-efficiency is important, it is not the only factor that should be considered in assessing a service. We consider the benefit to patients, staff working within the service and to the running of the hospital as a whole.

\section{ADVANTAGES}

\section{Experience}

For those working in $A \& E$ it provides a new dimension to the acute service, the opportunity to have experience of in-hospital follow up and continuity of care. It provides an ideal setting for teaching. Staff who were involved in the immediate management in $A \& E$ can benefit from the opportunity to reassess the patient and can also assist the diagnostic process and further management. Our ward provides extensive experience in the diagnosis and management of both acute and chronic head injury, complications of alcohol consumption, mild to moderately severe chest trauma, initial and delayed management of wounds affecting all parts of the body, soft tissue trauma and infections, and problems of intravenous drug abuse.

\section{Relationship with other specialties}

Our admission rates (3.3\%) were similar to those of Dallas and Mouzas (2-4\%) in $1981 .^{2}$ This benefits other departments as the service provides a safety net for those who are not seriously ill but who are also not fit for discharge. Brown $e t a l^{13}$ showed that the actual admission of patients with head injuries that meet the current criteria for admission is dependent partly upon ease of access to hospital beds and partly upon whether the admitting specialty has an interest in head injury. Where other surgical specialties with little interest in the problem bear the responsibility for admission, it is more likely that patients will be discharged inappropriately. Thus where a short stay ward is available patients may be observed until their condition either resolves or requires more specialist care. Other specialties are free to concentrate on those patients requiring more prolonged or specialist care. As a general rule we do not take responsibility for psychiatric patients or those suffering from drug overdose. A\&E wards vary in case mix, some with a more medical bias. In a sense there is no limit to who could be managed acutely on a short stay ward, so admission criteria need to be clearly defined and rigorously adhered to! 


\section{Patients}

Patients also benefit. Those who have minor disability leading to temporary inactivity may have a period of recuperation before returning to their homes. Many appreciate the continuity of care provided by a team of doctors from arrival at A\&E. Many who may not be fit for discharge because of head injury or alcohol intoxication are observed until they recover. Often these patients are aggressive or abusive and a separate area from those with major illness such as myocardial infarction is prudent.

\section{DISADVANTAGES}

Managing patients with poor social circumstances and little by way of medical illness in a single defined location may be attractive to other specialties but is not necessarily rewarding to those who do take on this responsibility. Often these patients appear ungrateful and uncooperative, and are consequently difficult to manage.

\section{Workload}

Forty four per cent of the workload of the ward involves patients who stay longer than 72 hours, and $20 \%$ involved the care of only three patients, under 65 years of age, suffering from major chronic head injury. The local authority has limited facilities for the rehabilitation of such "young" patients. There is a private unit but funding from the Health Board to support such a referral is limited. The ward also is not suitably resourced for the proper rehabilitation of such patients and while the commitment of staff is excellent given the circumstances, on occasion care is suboptimal. The "dumping" of inappropriate patients in an $A \& E$ ward may be another reason why some $A \& E$ specialists have been reluctant to take on the responsibility for short stay wards.

The fact that such a ward may be abused with patients staying for longer than appropriate and not just for a couple of hours of observation (as many may perceive the service) may discourage some from taking on the onus.

The ward is a high risk area. Other specialties may not consider the pathology sufficiently serious to require their care and patients may be considered low dependency and low priority. The potential for underestimating critical illness when the focus of the specialty is at the front door of $A \& E$ rather than the ward is very real.

Problems may also arise over admission criteria. The line of demarcation regarding whether a person should be admitted under $\mathrm{A} \& \mathrm{E}$ or another specialty may give rise to dispute. Specialties may be reluctant to accept referrals in the hope that $A \& E$ will take over the responsibility. If a ward did not exist then the problem may not arise.

It is of interest that with the reduction in beds before 1992 there was a sharp reduction in admission rate. One reason for this reduction may be that as long as beds are available medical staff could find a reason for admission, but when resources are trimmed further reasons will be found for not admitting patients. To a degree, therefore, the system may expand and contract to match supply and demand. An alternative concern is that patients who ideally should be admitted for a short period of observation may now be at greater risk of being turned away due to lack of resources.

\section{Consultant responsibilities}

Consultant responsibilities include the management of the ward, both administratively and clinically, in addition to the overall control of a large department with a high turnover of patients. The potential for misdiagnosis, mismanagement, and subsequent litigation is high. Consultant staff are expected to have a high profile both within and outside the department. When the management of a ward also with a high turnover of patients involves daily ward rounds and associated theatre work, such varied demands might explain why some are not eager to take on the responsibility of a ward.

\section{Staffing and financial considerations}

The demands of such a ward, and the high risk case load make appropriate resourcing mandatory. One of the first reports on $A \& E$ departments recommended that 30-35 beds should be provided per 100000 population for the management of emergency cases. ${ }^{14}$ In our department serving a population of 200000 , this would require 60-70 beds. Our current bed status is 20 , but possibly the initial recommendations were too high. A subsequent report recommended that one observation ward bed be available for every 5000 new patients seen. ${ }^{15}$ For this department that would mean the availability of 15 beds. Such a recommendation would depend upon the case mix of problems provided by the local population and the criteria for admission. While there are guidelines for bed allocation, there are no national guidelines for departmental staffing that would safely cover such a ward-a position that requires urgent addressing by the British Association for Accident and Emergency Medicine (BAEM). If one consultant per 25000 new patient attendances is adequate for the average $A \& E$ department then the addition of ward responsibilities would suggest that this figure should be reviewed. With current national SHO staffing problems, the safe viability of $A \& E$ wards is even more questionable. Many A\&E consultants would not consider taking responsibility for a ward without 24 hour middle grade cover and appropriate consultant numbers.

\section{CONCLUSION}

It is clear that short stay wards associated with $\mathrm{A} \& \mathrm{E}$ departments bring added responsibilities to the specialty. In areas with a high incidence of assault and alcohol related trauma, the provision of a separate area where patients may be managed for a short period is of value. This is feasible provided the service is fully resourced and meets the BAEM recommendations. Such wards should be recognised as acute clinical areas requiring 24 hour availability of experienced staff. 
We would like to thank the nursing staff of ward 24 for assistance in documentation and capture of missed patients, and Miss J McInally for helping with data entry.

1 Nuffield Provincial Hospitals Trust. Casualty services and their setting: a study in medical care. London: NPHT, 1960.

Dallos V, Mouzas GL. An evaluation of the functions of the short stay observation ward in the accident and emergency short stay observation ward in the acci

3 Clancy MJ. A one year prospective study of the use of an observation ward by an Accident and Emergency Department. Br f Accid Emerg Med 1989; Sept:9-10.

4 Ramaiah RS, Pal AK. The work load and cost implications of patients with self injury/assault in a short stay ward. $\mathrm{Br} f$ Accid Emerg Med 1987; Sept:5-6.

5 Morgan WJ. Letter. BMF 1981;282:398.

6 Beattie TF, Ferguson J, Moir PA. Short-stay facilities in accident and emergency departments for children. Arch Emerg Med 1993;10:177-80.

7 Beattie TF, Moir PA. Paediatric accident and emergency shortstay ward: a lyear audit. Arch Emerg Med 1993;10:181-6.
8 Abson EP. Letter. BMf 1981;282:398.

9 Rutherford W. Letter. BMF 1981;282:398-9.

10 US Department of Health and Human Services. International classification of diseases, 9th revision. Clinical modification, ed 3. Washington, DC: US Government Printing Office, 1989 .

11 Sniezek JE, Finklea JF, Graitcer PL Injury coding and hospital discharge data. $f A M A$ 1989;262:2270-2.

12 pital discharge data. JAMA 1989;262:2270-2. JW. Injury ibbeck BM, Runge JW, Thomason MH, Baker JW. Injury surveillance. a method for recording E codes for injured emergency department patients. Ann Emerg Med 1992;21:

13 Brown SR, Raine C, Robertson CE, Swann IJ. Management of minor head injuries in the accident and emergency department: the effect of an observation ward. $\mathcal{f}$ Accid Emerg Med 1994;11:144-8.

14 Standing Medical Advisory Committee. Accident and emergency services. London: HMSO, 1962. (Platt report.)

15 Casualty Surgeons Association. Accident and emergency ward. Report by the Clinical Services Standing Committee of the Casualty Surgeons Association. March, 1989.

\section{ADVANCED LIFE SUPPORT GROUP}

\section{Major Incident Medical Management and Support} Courses: to be held in various centres throughout the UK in 1996. This is a three day course in "life support style" designed to train health service personnel to provide an effective response at a major incident.

Fee $£ 300.00$

Advanced Paediatric Life Support Courses: to be held in various centres throughout the UK in 1996. This is a three day course designed to provide training which will enable doctors and nurses to deal efficiently with all paediatric emergencies. The course is modular and has sections on paediatric resuscitation, serious illness and serious injury.

Fee varies according to centre. Range $£ 300.00-£ 350.00$.

Inquiries for both courses to:

Jenny Antrobus

Advanced Life Support Group

A\&E Dept

Hope Hospital

Stott Lane

Salford M6 8HD

Tel 01617874345 